Jasdeep Singh', Syed Asad Rahman (1)

Nasreen Z. Ehtesham ${ }^{3}$, Subhash Hira ${ }^{4 凶}$ and Seyed E. Hasnain ${ }^{1,5 凶}$

${ }^{1}$ Department of Biochemical Engineering and Biotechnology, Indian Institute of Technology-Delhi, New Delhi, India. ${ }^{2}$ BioInception, Cambridge, UK. ${ }^{3}$ ICMR National Institute of Pathology, Safdarjung Hospital Campus, New Delhi, India. ${ }^{4}$ Department of Global Health, University of Washington, Seattle, WA, USA. ${ }^{5}$ Department of Life Science, School of Basic Sciences and Research, Sharda University, Greater Noida, India.

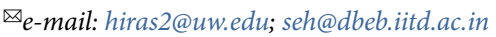

Published online: 27 May 2021

https://doi.org/10.1038/s41591-021-01397-4

References

1. MRC Centre for Global Infectious Disease Analysis \& Imperial College London. https://github.com/mrc-ide/global-lmic-reports/ tree/master/data (accessed 11 May 2021).

2. Singh, J. et al. Viruses 13, 439 (2021).

3. Julia, L.M. et al. Outbreak.info https://outbreak.info/ (accessed 11 May 2021).

4. Li, Q. et al. Cell 182, 1284-1294.el289 (2020).

5. Hacisuleyman, E. et al. N. Engl. J. Med. https://doi.org/10.1056/ NEJMoa2105000 (2021).

6. Sabino, E. C. et al. Lancet 397, 452-455 (2021)

7. Mukherjee, A. et al. Epidemiol. Infect. 149, e82 (2021).

8. Dong, E., Du, H. \& Gardner, L. Lancet Infect. Dis. 20, 533-534 (2020).
9. European Centre for Disease Prevention and Control. https://www.ecdc.europa.eu/en (accessed 23 April 2021). 10. Shu, Y. \& McCauley, J. Euro Surveill. 22, 30494 (2017).

\section{Acknowledgements}

We gratefully acknowledge all researchers who shared genetic sequence data via the GISAID Initiative. JC Bose National Fellowship provided the funding.

\section{Author contributions}

Conceptualization, all authors; Supervision, N.Z.E., S.H. and S.E.H.; writing (original draft), all authors; writing (review and editing), S.A.R., N.Z.E., S.H. and S.E.H.

\title{
Brazil needs a coordinated and cooperative approach to tackle COVID-19
}

To the Editor-After more than 14 months under siege, Brazilians continue to suffer as they see thousands of people dying every day, killed by the fast-moving respiratory pathogen SARS-CoV-2. Families are struggling to secure their livelihoods, quell hunger and, in some cases, adjust to the long-term toll of having survived infection with SARS-CoV-2. With the surge in cases, overcrowding of hospitals and high lethality, those on the front lines understand that Brazil is at war with COVID-19. The assault has been brutal ${ }^{1}$. A quarter of all deaths from COVID-19 in Brazil were officially recorded in April 2021. Meanwhile, a SARS-CoV-2 variant of concern, lineage P.1 (B.1.1.28.1), continues to be detected in an ever-increasing share of infections, on the basis of the small number of genomes sequenced across the country ${ }^{2}$.

Many factors explain why the toll of the pandemic on Brazil has been so extraordinary, including its close transport connectivity with world markets, the marked socioeconomic vulnerabilities of its many populations ${ }^{3}$, and persistent inequities. A crucial factor in the COVID-19 crisis in Brazil is the lack of central command, strategic planning and clear evidence-based recommendations from the outset ${ }^{4}$. As the fourth minister of health to be appointed since the pandemic began attempts to guide the response, Brazil remains the epicenter of the COVID-19 pandemic in Latin America. The battle against SARS-CoV-2 will be lost without a central command and leaves behind a bitterly divided country.
To win, Brazil needs a unified front coordinated with a common goal: eliminating COVID-19's assault. Multiple fronts must be coordinated, and weapons need to be mobilized commensurate with the threat at hand. The plan must begin through recognition of what is working. There are numerous lessons from other countries and from within Brazil. In the few exceptional cases in which stricter lockdowns were imposed, such as in Araraquara, São Paulo, and surveillance strategies focused on the primary care response, such as in São Caetano do Sul, São Paulo, these measures proved to be extremely effective. The strategy must be clear, coherent and coordinated. Leaders who can build consensus are badly needed to help identify a common agenda of fundamental principles and the policies that can be adopted as part of a national pact.

First, clear and concise evidence-based communication to society is crucial. Handling the COVID-19 pandemic demands that national leaders act to build trust and cooperation. Science has become visible and more valued in society, and it is time for the nation's leaders to show that they are ready to use science as the most important weapon in tackling COVID-19. There is no longer room for government officials to prioritize political opportunism and the spreading of fake news 5 .

Second, mathematical models confirm that Brazil needs to adopt stricter measures of physical distancing and, in some states, a lockdown ${ }^{6}$. In contrast, non-pharmaceutical interventions need to be coordinated across states, and social assistance programs need to be targeted to meet the needs of vulnerable populations, such as the economically disadvantaged, racial and ethnic minorities, low-income children, the elderly, the homeless, and those who are infected with human immunodeficiency virus or have other chronic health conditions. Polls suggest that the majority of Brazilians support stricter physical-distancing policies despite the short-term economic hardship 7 . However, in the absence of stricter policies, the level of adherence to social distancing is falling, in part because the majority of people in Brazil cannot work from home.

Third, a strict lockdown will be effective only if the country's ability to predict and respond to SARS-CoV-2 transmission is improved. Testing programs need to be ramped up and focused on identifying people who are transmitting the virus to others, combined with tracing and testing of their contacts. In regions with limited laboratory infrastructure, the widespread use of antigen tests, with their faster turnaround times, will contribute to earlier quarantining. The rapid scaling-up of testing needs to be aligned with a vastly expanded effort to undertake genetic sequencing to detect existing and new variants of concern.

Fourth, the speed of efforts to vaccinate the Brazilian population needs to be increased to warp speed. Local vaccine-finishing production is currently 
at a standstill due to delays in the import of active pharmaceutical ingredients and deliveries below agreed levels. Even though vaccination has been progressing slowly, there are already emerging signs that vaccines are helping to curb the severity of infection and death rates ${ }^{8}$. With limited global vaccine supplies, national leaders need to ensure that they prepare the population for the long-term use of non-pharmaceutical interventions until vaccines either are locally produced in Brazil or arrive via additional procurements and pending purchases through the COVAX initiative.

Fifth, it is time for Brazil to search beyond its borders and reach out to the international community, for its efforts will be successful only if they are aligned with those of its neighbors and allies. Governments and the private sector in high-income countries must be reminded of their obligation to match words of solidarity with concrete actions. Rather than focusing efforts on introducing vaccine passports and propagating vaccine nationalism, Europe and the United States should lead efforts to ensure that the costs of tests, drugs, medical equipment and vaccines are made affordable to ensure an adequate supply in the Global South. There is no excuse for delays in delivering vaccine reagents that were agreed upon in contracts, especially as trials for the SINOVAC and ChAdOxl vaccines were conducted in, and partially paid for by, Brazil ${ }^{9,10}$.

The COVID-19 pandemic has been painful for Brazil, but we are confident that it has served as a catalyst for building a more resilient nation. We co-teach a university-wide graduate course with other colleagues at the University of São Paulo, which we have opened as a public course with students and faculty attending from across Brazil each week. In this course we emphasize that the pandemic in Brazil should be used as a means of identifying policies that are not just about recovery, but are about creating a safer, more sustainable and more equitable society.

Brazilian society has already started reorganizing itself. Through programs such as Todos pela Saúde and Todos pela Vacinas, broad coalitions have mobilized to campaign for more funding for public health, emergency assistance and vaccines. Policy reforms are being debated through initiatives such as the Brazilian Network of Women Scientists so that decisions are enacted with equity. Moreover, international networks have been instrumental in supporting these local initiatives. Brazilian society has responded to the call to arms. The time to act is now.
Lorena G. Barberia(D) 1 ,

Silvia Figueiredo Costa² and Ester C. Sabino ${ }^{2}$

${ }^{1}$ Department of Political Science, Universidade de São Paulo, São Paulo, Brazil. ${ }^{2}$ Department of Infectious Diseases, Faculdade de Medicina da Universidade de São Paulo, São Paulo, Brazil.

$\bigotimes_{e-m a i l: l o r e n a b a r b e r i a @ u s p . b r}$

Published online: 21 June 2021

https://doi.org/10.1038/s41591-021-01423-5

References

1. Ranzani, O. T. et al. Lancet Respir. Med. 9, 407-418 (2021).

2. Faria, N. R. et al. Science 372, 815-821 (2021).

3. Li, SabrinaL. et al. BMJ Glob. Health 6, e004959 (2021).

4. Castro, M. C. et al. Science 372, 821-826 (2021).

5. Barberia, L.G. et al. Rede de Pesquisa Solidária em Políticas Públicas e Sociedade https://redepesquisasolidaria.org/wpcontent/uploads/2021/05/boletimpps-31-22maio2021.pdf (2021).

6. Imperial College COVID-19 response team. https://mrc-ide. github.io/covid19-short-term-forecasts/index.html (accessed 24 May 2021).

7. DataFolha. http://media.folha.uol.com.br/datafolha/2020/ 05/27/5aabciel8238c225b8a943e4b6ed8a9802pand5.pdf (2020).

8. Victora, C. G., Castro, M. C., Gurzenda, S., \& Barros, A. J. Preprint at medRxiv https://doi.org/10.1101/2021.04.27.21256187 (2021).

9. Palacios, R. et al. Preprint at https://doi.org/10.2139/ssrn. 3822780 (2021).

10. Faria, Elizabeth, et al. Preprint at medRxiv https://doi.org/ 10.1101/2021.04.12.21255308 (2021).

Author contributions

All authors conceived of and drafted the manuscript and contributed to revision of the manuscript.

Competing interests

The authors declare no competing interests. 